\title{
Diagnosis and management of
}

\section{gastrointestinal causes of chest pain of}

\section{uncertain origin}

\begin{abstract}
John de Caestecker MD FRCP, Consultant Physician and Gastroenterologist, Glenfield Hospital, Leicester
\end{abstract}

\section{Clin Med JRCPL 2002;2:402-5}

Recurrent central chest pain is a common clinical problem. Not surprisingly, most patients will want to know if the symptom arises from the heart and, if so, whether they are at risk of a sudden cardiac event. In general practice in the UK more than half such patients turn out not to have cardiac disease ${ }^{1}$, while about $10 \%$ of the more highly selected group who end up having diagnostic coronary angiography have no abnormality of the epicardial arteries. These patients have a low mortality, but up to $75 \%$ suffer persistent symptoms and a poor quality of life over long follow-up periods (2-10 years) and $30-50 \%$ of them never return to work and are unable to carry out household tasks. Many remain convinced that they have a cardiac disorder, even if an alternative diagnosis has been proposed, continuing to take cardiac medications and to use medical resources $^{1-3}$.

\section{How to investigate?}

Positive diagnosis of non-cardiac chest pain as early as possible might prevent such a state of affairs. It has been suggested that patients with a 10-year risk of a cardiac event higher than $20 \%$ (based on published risk tables) should be investigated for cardiac disease even if the pain is 'atypical' for angina pectoris ${ }^{2}$.

Careful analysis of the symptom pattern does not reliably differentiate patients who eventually turn out to have cardiac disease and those with other aetiologies. The quality and distribution of the pain are not discriminatory - even exertional pain may turn out to have a non-cardiac cause $\mathrm{c}^{2,4}$. The features summarised in Table 1 make a non-cardiac diagnosis more likely ${ }^{4}$. Oesophageal value, probably because heartburn is such a common symptom in the general population, but some other symptoms can point to an alternative diagnosis (Table 2).

Physicians with a particular specialty interest may be more likely to diagnose a disorder with which they are familiar (indeed this is reflected in published clinical series), but this should not deter them from taking a broad and open-minded view. There may be more than one trigger to the pain, while psychological factors are likely to be

Further investigation should be guided

Table 1. Features in the history suggestive of a non-cardiac origin of symptoms ${ }^{4}$.

- Pain continuing as a background ache for hours

- Variation in the amount of exercise causing pain

- Pain commencing up to $10 \mathrm{~min}$ after exercise had stopped

- Pain waking from sleep at night symptoms such as heartburn are of little responsible for persistence of symptoms.

by symptoms and risk assessment: cardiac disease should be excluded as rapidly as possible, particularly where the risk is moderate or high. Low-risk patients, such as premenopausal women with no coronary risk factors and atypical pain, will not usually require cardiac investigation and tests should be directed towards potential non-cardiac causes $^{2}$. Non-invasive tests are appropriate, such as exercise ECG or radionuclide myocardial perfusion scans (with the provisos mentioned below). Coronary angiography should usually be reserved for patients at risk if non-invasive tests are positive or equivocal.

Exertional angina pectoris is a descriptive symptom complex. Heberden ${ }^{5}$ speculated that the symptoms might arise from 'a strong cramp, or an ulcer or both'. However, some cardiologists consider this symptom to be diagnostic of myocardial ischaemia. A number of potential cardiac disorders have therefore been proposed, including microvascular angina. These require complex investigation, often available only in specialised centres with a research interest in the syndrome of anginal pain with normal epicardial arteries. There is continued debate, first, about the specificity of these tests (they are often highly invasive, so data in true 'control' subjects are sparse) and, second, about their true prevalence in patients with chest pain of uncertain origin since most case series include highly selected groups of patients ${ }^{2}$.

It is appropriate to mention some caveats:

- False positive exercise ECGs are common in middle-aged women

\section{Key Points}

Non-cardiac chest pain is a chronic, potentially disabling condition

Cardiac disease should be rapidly excluded in those with risk factors for ischaemic heart disease

Gastro-oesophageal reflux is the commonest gastrointestinal cause

A therapeutic trial of high-dose proton pump inhibitor is a valuable diagnostic aid

Antidepressants may benefit some patients

KEY WORDS: gastro-oesophageal reflux, non-cardiac chest pain, oesophagus 
with chest pain. Corroborative myocardial perfusion scanning is often appropriate in this situation. Resting or exercise ECG showing left bundle branch block should raise the possibility of cardiomyopathy and lead to echocardiography.

- Investigation directed at elucidating non-cardiac conditions should be guided by the history and examination. Gallstones have a population prevalence of about $12 \%$, so there is little point in demonstrating 'incidental' gallstones by abdominal ultrasonography if the symptoms do not support this as a cause of pain.

- Oesophageal motility abnormalities are also found quite commonly in asymptomatic individuals, so there is little to be gained by referring patients for complex tests if symptoms such as additional dysphagia are absent.

\section{Gastrointestinal investigations}

Appropriate initial investigation guided by symptoms (Table 2 ) will usually be endoscopy, with empirical treatment of peptic ulcer or oesophagitis if found. Other gastrointestinal (GI) conditions should be sought only if additional symptoms suggest they may be present.

Enthusiasm for detecting oesophageal disorders has waxed and waned over the last 30 years. In patients appropriately investigated, the percentages found to have oesophageal abnormalities are shown in Fig 1. Gastro-oesophageal reflux (GOR) is by far the commonest disorder and is the most rewarding to treat $^{7}$.

\section{Investigations for gastro-oesophageal reflux}

Only about $30 \%$ of patients with chest pain eventually diagnosed with reflux have endoscopic oesophagitis ${ }^{7}$. The yield of barium radiology is similar. A therapeutic trial of proton pump inhibitors is a useful and simple initial test. A one to three week trial with high doses (eg omeprazole $60-80 \mathrm{mg}$ daily) is usually sufficient. This test has been reported to

Table 2. Features suggesting an alternative non-cardiac diagnosis.

Features

Gastroenterological disorders

Chest pain radiating to the back after meals

Chest pain waking the patient from sleep

Dysphagia and/or pain on swallowing

Left chest pain relieved by defaecation or the passage of flatus

\section{Rheumatological disorders}

Chest and/or left arm pain related to neck or arm movement

Chest - back pain; possibly 'girdle' distribution; relation to posture changes

Anterior chest pain with tenderness and/or swelling of costochondral junctions

\section{Psychiatric/psychological disorders} Phobic symptoms precipitated by certain situations; attacks accompanied by extreme anxiety with appropriate physical symptoms Abnormal attitudes and beliefs about symptoms, eg fear of sudden death, conviction of heart disease despite objective evidence

Stressful life events (loss, rejection etc)

\section{Disorder}

\section{Gallstones}

Peptic ulcer disease (especially if long symptom-free intervals) Gastro-oesophageal reflux

Gastro-oesophageal reflux Oesophageal motility disorders

'Splenic flexure syndrome'* variant of irritable bowel syndrome

\section{Cervical spondylosis \\ Cervical rib}

Thoracic spine disorders

\section{Costochondritis}

\author{
Agoraphobia \\ Panic attacks \\ Hyperventilation syndrome \\ Anxiety \pm depression compounding \\ symptoms
}

Anxiety \pm depression compounding symptoms

*Splenic flexure syndrome: pain in left upper quadrant radiating to chest, thought to be due to build-up of air in the splenic flexure of the colon. Reproduced by balloon distension in this area and relieved by passage of stool or flatus have a sensitivity of $78 \%$ and a specificity of $86 \%$ in patients with chest pain of uncertain origin ${ }^{8}$. However, the specificity is in some doubt because patients with functional upper GI disorders are known to have a high placebo response. Furthermore, a proportion of patients with proven GOR fail to suppress gastric acid production even on high doses of proton pump inhibitors.

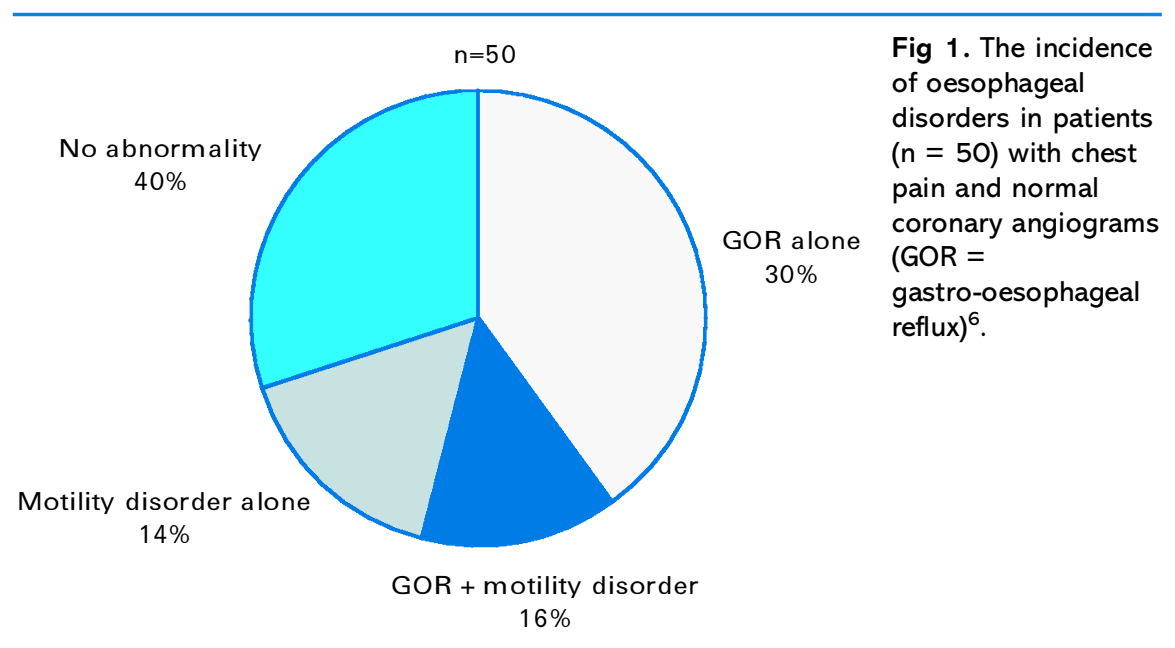




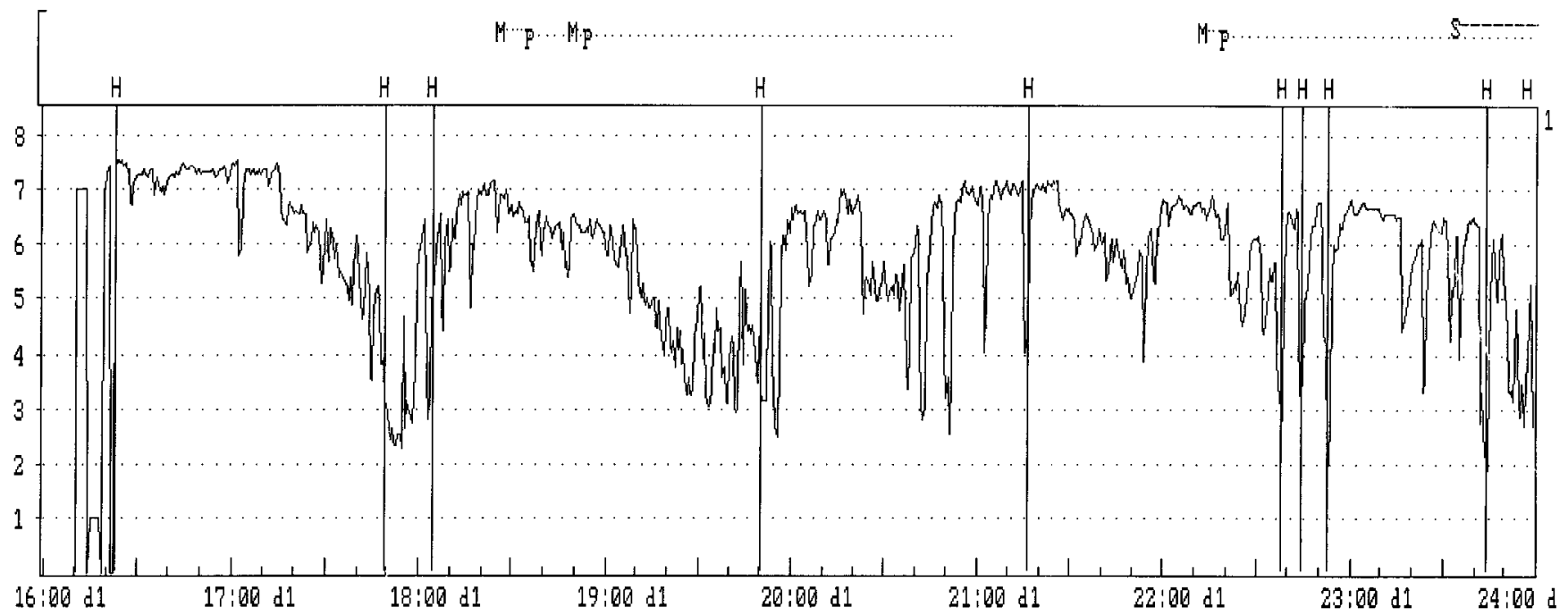

Fig 2. A portion of a 24-hour $\mathrm{pH}$ tracing in a patient with chest pain. $\mathrm{X}$-axis = time in hours; $\mathrm{Y}$-axis $=\mathrm{pH}$ scale. Reflux events are denoted by sudden falls in $\mathrm{pH}$ to below 4. Many events correspond with periods of low intra-oesophageal $\mathrm{pH}(\mathrm{H}=\mathrm{the}$ event marker has been activated due to spontaneous chest pain; $M=$ meals; $p=$ postprandial period; $S=$ sleep).

Prolonged 24-hour oesophageal $\mathrm{pH}$ monitoring remains the most sensitive tool for proving the relevance of GOR to chest pain (Fig 2). The amount of reflux can be quantified using established normal values. The test also allows correlation of symptoms with reflux events. If many chest pain events occur during the period of monitoring, it is possible to derive a 'symptom index' to express the degree of association of reflux and symptoms. In patients who develop no symptoms during the period of monitoring, the finding of excess reflux should lead to a trial of anti-reflux therapy.

\section{Investigating oesophageal motility}

Some of the reasons why enthusiasm for investigating oesophageal motility has waned over the past $10-15$ years $^{9}$ are summarised in Table 3. Oesophageal motility abnormalities are rarely responsible for chest pain. Oesophageal manometry is valueless for most patients being investigated for chest pain of uncertain origin ${ }^{9,10}$. Detailed investiga-

Table 3. Some reasons why investigation of oesophageal motility is now less frequently performed.

- Abnormalities such as 'nutcracker' oesophagus* are simply an exaggeration of normal motility

- Stress leads to similar abnormalities

- Oesophageal manometric abnormalities are poorly reproducible in the context of chest pain

- Spontaneous chest pain is rarely associated with abnormal motility during ambulatory monitoring of oesophageal motility

- Abnormalities thought diagnostic of oesophageal spasm during oesophageal manometry are poorly predictive of spontaneous symptomatic oesophageal spasm detected during prolonged ambulatory monitoring of oesophageal motility

- Correction of abnormal motility by calcium-channel antagonists in controlled trials does not result in improvement of chest pain

tions for oesophageal motility disturbances should be undertaken in patients with additional dysphagia and/or odynophagia (pain on swallowing).

Ideally, abnormalities should be demonstrated by more than one investigation. The most useful investigations in this situation are the video barium swallow with bread, ambulatory oesophageal motility and $\mathrm{pH}$ measurements ${ }^{10}$ - although the last are likely to be helpful only in patients with daily symptoms.

\section{Oesophageal provocation tests}

The acid perfusion test may provoke symptoms, but control saline perfusion should also be performed. A positive acid perfusion test indicates an acidsensitive oesophagus and does not necessarily equate to GOR. Patients with an 'irritable oesophagus', but no abnormal GOR, may have a positive test ${ }^{11}$.

Pharmacological provocation tests, of which the edrophonium test has been the most popular, are now rarely performed. A positive test was originally thought to identify disordered motility, but this is now no longer thought correct. The edrophonium test probably also identifies patients with an irritable oesophagus ${ }^{11}$; if performed, it should be accompanied by a control saline injection. 


\section{Treatment of patients with chest pain of uncertain origin}

It is clear from recent follow-up studies that the mere diagnosis of a non-cardiac abnormality does not reduce the long-term morbidity. In some studies, improvement in terms of less use of medical facilities and ability to return to work was confined to small patient subgroups. Many patients do not accept or remember that an alternative cause of chest pain has been found ${ }^{12}$. It is sensible, therefore, to reinforce this message frequently.

Perimenopausal women with chest pain may improve if prescribed hormone replacement therapy. One controlled trial documents the efficacy of omeprazole in patients with chest pain and abnormal reflux on prolonged $\mathrm{pH}$ monitoring, but there was a high placebo response in this study ${ }^{13}$. Another uncontrolled study found the intriguing result that prolonged $\mathrm{pH}$ monitoring does not predict response to omeprazole ${ }^{14}$.

Abnormal sensory perception has been documented in the oesophagus and heart in patients with oesophageal chest pain ${ }^{15}$, which may account for the observed response to low-dose antidepressant therapy in several studies. However, quality of life may not be improved since many of these patients suffer from distressing side effects ${ }^{16}$. One recent study reported a beneficial effect and few side effects of a selective serotonin reuptake inhibitor in patients with chest pain of uncertain origin. This effect did not appear to result from changes in anxiety or depression ${ }^{17}$.

Patients with hyperventilation benefit from respiratory retraining ${ }^{2}$. Some patients may benefit from psychological intervention, particularly cognitive behavioural therapy ${ }^{2}$, efficacy for which has been shown in several controlled trials. Patients who may benefit are those with phobic features, morbid preoccupations and abnormal attitudes and beliefs (see Table 2).

\section{References}

1 Gill D, Mayou R, Dawes M, Mant D. Presentation, management and course of angina and suspected angina in primary care. J Psychosom Res 1999;46:349-58.

2 Chambers J, Bass C. Atypical chest pain: looking beyond the heart. QJM 1998;91: 239-44.

3 Potts SG, Bass CM. Psychosocial outcome and use of medical resources in patients with chest pain and normal or near-normal coronary arteries: a long-term follow-up study. QJM 1993;86:583-93.

4 Davies HA, Jones DB, Rhodes J, Newcombe RG. Angina-like esophageal pain: differentiation from cardiac pain by history. J Clin Gastroenterol 1985;7:477-81.

5 Heberden W. Some account of a disorder of the breast. Med Trans Coll Phys Lond 1772; 2:59-67.

6 DeMeester TR, O’Sullivan GC, Bermudez G, Midell AI et al. Esophageal function in patients with angina-type chest pain and normal coronary angiograms. Ann Surg 1982;196:488-98.

7 Richter JE. Chest pain and gastroesophageal reflux disease. J Clin Gastroenterol 2000; 30(Suppl 3):S39-41.

8 Fass R, Fennerty B, Ofman JJ, Gralnek IM et al. The clinical and economic value of a short course of omeprazole in patients with noncardiac chest pain. Gastroenterology 1998;115:42-9.

9 Valori RM. Nutcracker, neurosis, or sampling bias? Review. Gut 1990;31:736-7.

10 Barham CP, Gotley DC, Fowler A, Mills A, Alderson D. Diffuse oesophageal spasm: diagnosis by ambulatory 24 hour manometry. Gut 1997;41:151-5.

11 Vantrappen G, Janssens J, Ghillebert G. The irritable oesophagus - a frequent cause of angina-like pain. Lancet 1987;i:1232-4.

12 de Caestecker JS, Bruce GM, Heading RC. Follow-up of patients with chest pain and normal coronary arteriography: the impact of oesophageal investigations. Eur J Gastroenterol Hepatol 1991;3:899-905.

13 Achem S, Kolts BE, MacMath T, Richter J et al. Effects of omeprazole versus placebo in treatment of noncardiac chest pain and gastroesophageal reflux. Dig Dis Sci 1997; 42:2138-45.

14 Chambers J, Cooke R, Anggiansah A, Owen W. Effect of omeprazole in patients with chest pain and normal coronary anatomy: initial experience. Int J Cardiol 1998; 65:51-5.

15 Richter JE, Barish CF, Castell DO. Abnormal sensory perception in patients with esophageal chest pain. Gastroenterology 1986;91:845-52.

16 Cox ID, Hann CM, Kaski JC. Low dose imipramine improves chest pain but not quality of life in patients with angina and normal coronary angiograms. Eur Heart $J$ 1998;19:250-4.

17 Varia I, Logue E, O’Connor C, Newby K et al. Randomized trial of sertraline in patients with unexplained chest pain of noncardiac origin. Am Heart J 2000;140:367-72. 